\title{
ADAPTASI FONT HURUF LATIN DARI KARAKTER VISUAL TIPOGRAFI AKSARA MAKASSAR 'LONTARA'
}

\author{
Adhreza Brahma ${ }^{1}$ \\ ${ }^{1}$ Program Magister, Fakultas Seni Rupa dan Desain, Institut Teknologi Bandung \\ Komplek Griya Cigadung Baru No. B15 \\ e-mail: ezzazebra@gmail.com
}

\begin{abstract}
Abstrak. Aksara adalah bagian dari budaya yang menentukan tingkat berpikir manusia serta karakteristik dan identitas sebuah suku bangsa. Dengan masuknya era modern, maka komunikasi di Indonesia pada umunya dipelajari dengan menggunakan huruf latin dengan tujuan agar dipakai secara universal.

Hasil penelitian merujuk pada identifikasi visual dari font 'Angled' yang merupakan inovasi dari sistem penulisan yang digunakan para pendahulupendahulu suku Bangsa Makassar tersebut dimulai dari struktur anatomi, karakteristik visual, dan studi elemen geometris hingga dapat diaplikasikan menjadi bentuk baru berupa huruf digital (typeface) dari aksara Lontara menjadi aksara Latin (Roman).
\end{abstract}

Kata kunci: aksara, typeface, tipografi

Abstract. Characters are the part of the culture that determines the level of human thinking as well as the characteristics and identity of an ethnic. In this modern era, communication in Indonesia generally always using the Latin letters with the aim to be used universally.

The results of this study are refers to the visual identification of the fonts 'Angled' which is an innovation of the writing system, that used by the predecessors of Makassar tribes, starting from anatomical structures, visual characteristics, and geometric element studies to be applied as a new form in digital typeface from Lontara characters into Latin script (Roman).

Keywords: characters, typeface, typography

\section{Pendahuluan}

Setiap huruf merangkai setiap kata dan setiap kalimat, juga mengantarkan pada esensi dari bahasa tulis yang mengungkapkan informasi. Selain berfungsi sebagai alat komunikasi, huruf mempunyai karakteristik tersendiri untuk memberikan kesan visual yang ingin disampaikan. Merujuk pada Sihombing (2001), tipografi sebagai ilmu dalam menyusun huruf yang tepat dalam desain mampu menerjemahkan apa yang ingin disampaikan sehingga terbentuklah korelasi antara fungsi dan estetika. 
Seiring perkembangan pengunaan huruf Latin yang universal dan media komputer untuk keperluan menulis yang lebih praktis, terciptalah font-font baru yang diciptakan oleh para type designer dengan ide-ide yang diterjemahkan kedalam 52 huruf berikut dengan angka dan simbol-simbol.

Dalam konteks eksplorasi ide untuk merancang font baru, aksara budaya lokal mampu menghasilkan karakteristik yang beragam [2]. Karena secara visual, aksara yang tercipta pada setiap suku bangsa, mencerminkan pula karakteristik individual dari berbagai daerah. Karakteristik ini didasari dari representasi yang terlihat antara bentuk-bentuk visual aksara budaya dengan cara pengucapan bahasa verbal, yang menjadi ciri suku tersebut.

Dalam penelitian sebelumnya yang dilakukan oleh Fauziah (2013), Lontara adalah aksara tradisional masyarakat Bugis. Bentuk aksara Lontara menurut budayawan Mattulada seorang profesor berasal dari "sulapa eppa wala suji". Wala suji berasal dari kata wala yang artinya pemisah/pagar/penjaga dan suji yang berarti putri. Wala Suji adalah sejenis pagar bambu dalam acara ritual yang berbentuk belah ketupat. Sulapa eppa (empat sisi) adalah bentuk mistis kepercayaan Bugis-Makassar klasik yang menyimbolkan susunan semesta, api-air-angin-tanah. Huruf lontara ini pada umumnya dipakai untuk menulis tata aturan pemerintahan dan kemasyarakatan. Naskah ditulis pada daun lontar menggunakan lidi atau kalam yang terbuat dari ijuk kasar (sembilu).

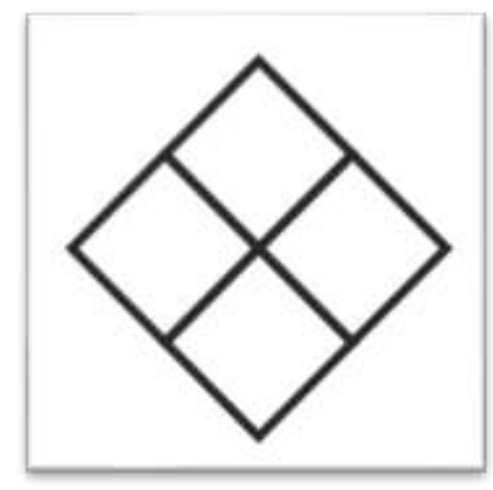

Gambar 1: Sulapa Eppa

Sumber: Dokumentasi Pribadi (2014)

\section{Analisis Aksara Lontara}

Pengunaan aksara Lontara secara signifikan berbeda dengan huruf latin yang selama ini telah digunakan bahkan jika dilihat dari kebiasaan, aksara tersebut tidak familiar dibandingkan dengan huruf latin yang sudah dikenalkan dan terbiasa digunakan untuk komunikasi sehari-hari. 
Perlu adanya penyesuaian dengan membandingkan antara aksara Lontara dengan huruf latin yang berbeda antara lain segi teknis pengunaan dan juga segi visual. Teknis membaca aksara Lontara hampir sama dengan aksara suku bangsa lain di Indonesia yakni memakai penggalan suku kata (ca-ja-nya-nca) di lain pihak, huruf Latin digunakan dengan huruf tunggal yakni setiap huruf disusun untuk menjadi sebuah kata yang bermakna. Huruf latin termasuk dalam jenis aksara fonetik yaitu jenis aksara yang berupa lambang fonem (ab-c-d-e).

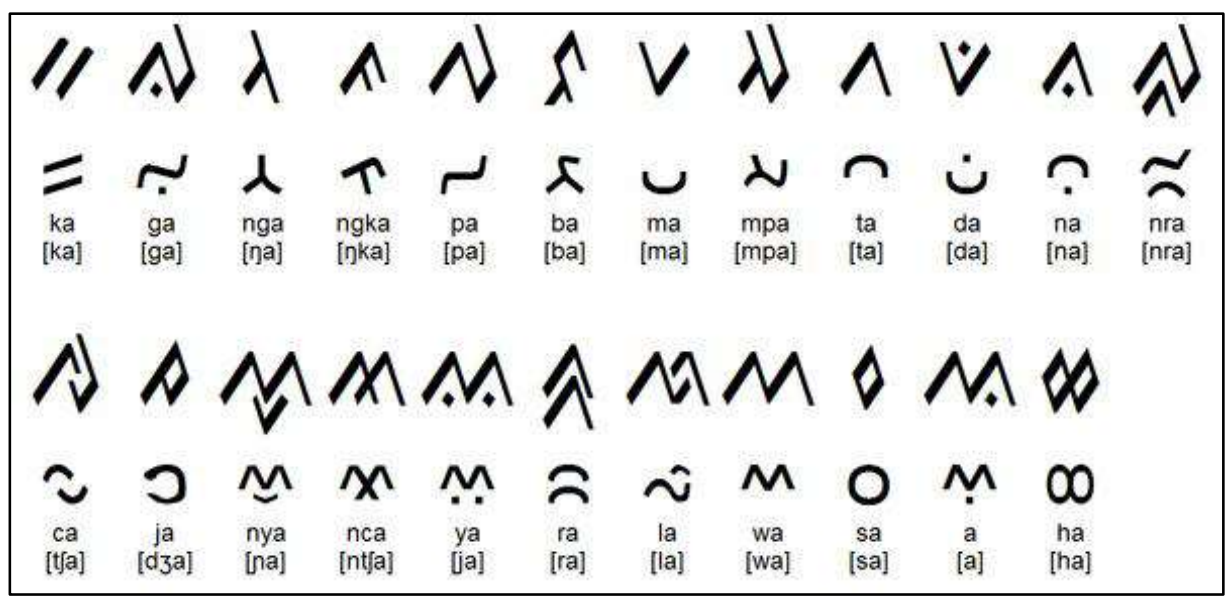

Gambar 2: Aksara Lontara

Sumber: http://id.wikipedia.org/wiki/Aksara_Lontara\#Konsonan

(20 November 2014)

Dari segi visual, aksara Lontara mempunyai karakteristik yang sangat konsisten dengan visual konstruksi garis, ketebalan, dan bentuk yang merujuk pada satu bentuk.

\section{Karakteristik Aksara Lontara}

1. Bentuk paling dasar merujuk pada objek segitiga.

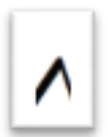

2. Kesan kaku yang ditunjukkan dengan adanya sudut mati, tidak lengkung.

3. Prinsip objek meliputi bertumpuk (huruf "nya"), berpotongan (huruf "ya"), penggabungan (huruf "ha"). 
4. Pengunaan spasi, leading, dan kerning realtif jauh dan menimbulkan ruang kosong merujuk pada bentuk dasar segitiga.

5. Stroke (garis) menggunakan garis tebal dan tipis secara bergantian.

\section{Anatomi Huruf}

Anatomi huruf Latin yang telah banyak dirancang dan digunakan secara digital mempunyai struktur yang rata dan teratur agar keterbacaan suatu huruf dapat dimasksimalkan. Posisi semua karakter (huruf, angka, symbol, dan tanda baca) yang terdapat pada sebuah typeface mempunyai sistem yang terbentuk dari sebuah bebrrapa garis maya secar horizontal yang menentukan baseline (posisi huruf ditulis), capline (posisi tinggi huruf kapital), dan meanline (posisi tinggi huruf kecil). Pada aksara Lontara, struktur penulisan tersebut tidak lengkap karena aksara tersebut cenderung menggunakan kembali bentuk dasar, sehingga hanya mengandalkan dengan penulisan yang lurus saja.

Sistem pada aksara Lontara juga tidak mempunyai sistem perancangan secara vertical, maka berbeda dengan huruf Latin yang mempunyai struktur penulisan yakni ascender (garis batas bagian atas), descender (garis batas bagian bawah), dan xheight (garis batas huruf $\mathrm{x}$ ).Aksara Lontara tampak dominan dengan cara penulisan horizontal.

\section{Studi Elemen Visual}

Bentuk penyederhanaan aksara Lontara merujuk pada analisis tentang cara penulisan aksara tersebut yang berfokus pada satu bentuk yakni segitiga. Hal tersebut menyebabkan bagian-bagian dalam aksara yang merupakan pengulangan. Dengan asumsi tersebut, maka bentuk yang akan dikombinasikan dengan huruf Latin merujuk pada anatomi segitiga utuh untuk dijadikan konsep perancangan tipografi.

\section{Pola Huruf}

Perancangan tipografi dengan menggunakan prinsip modular adalah dengan menggunakan satu objek sebagai bentuk utama untuk dijadikan pedoman perancangan keseluruhan huruf, sehingga pada akhirnya bentuk yang dihasilkan adalah bersudut sama. 

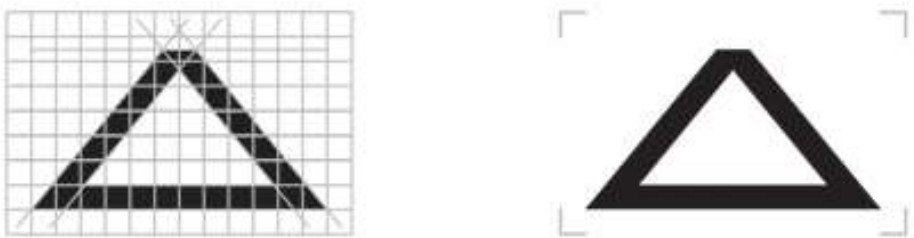

Gambar 3: Sistem perancangan modular

Sumber: Dokumentasi Pribadi (2009)

Teknis penulisan aksara Lontara dirancang mengikuti beberapa huruf yang merupakan pengulangan dari bentuk dasar agar terlihat lebih dinamis, sehingga penulisan yang akan dilakukan mengikuti pola zig-zag yakni secara manual, pengunaannya harus ditulis secara bergantian antara huruf-besar dan huruf kecil.

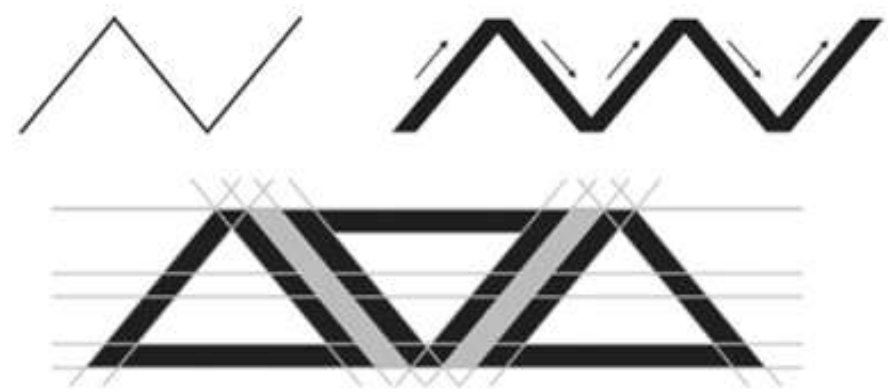

Gambar 4: Sistem penulisan Modular

Sumber: Dokumentasi Pribadi (2009)

Dengan modul tersebut dapat terlihat bahwa pengunaan garis maya horizontal digunakan untuk mengatur secara rapih setiap karakter dan membuat general bentuknya tanpa uppercase dan lowercase. Namun dalam pengunaannya, karakter uppercase merupakan bentuk segitiga yang menghadap keatas, sedangkan lowercase adalah bentuk segitiga yang menghadap ke bawah.

\section{Desain}

Modul yang telah ditentukan dari hasil proses penelitian menjadi pedoman untuk merancang setiap huruf Latin dimulai dengan sketsa-sketsa untuk mencari segala alternatif yang memungkinkan untuk dipakai dan dapat diaplikasikan. Maka pada tahap ini penelitian berfokus pada bagaimana tingkat readability dan legibility yang akan ditunjukkan. 


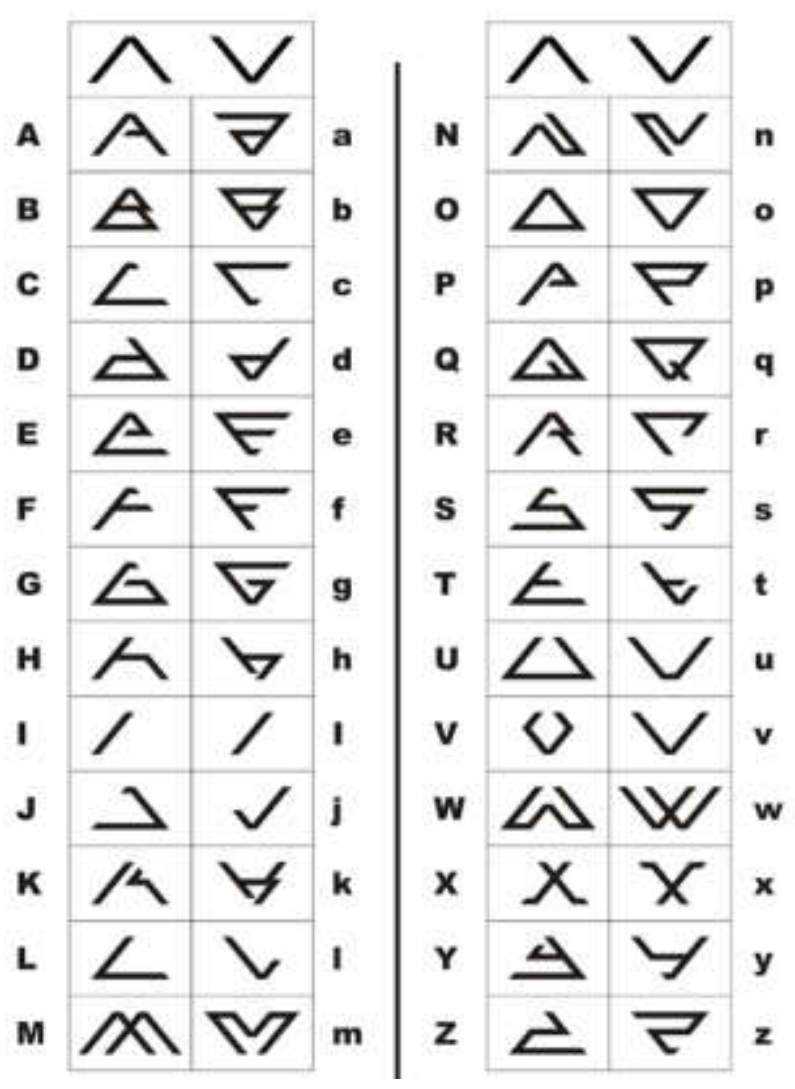

Gambar 5: Finalisasi Huruf

Sumber: Dokumentasi Pribadi (2009)

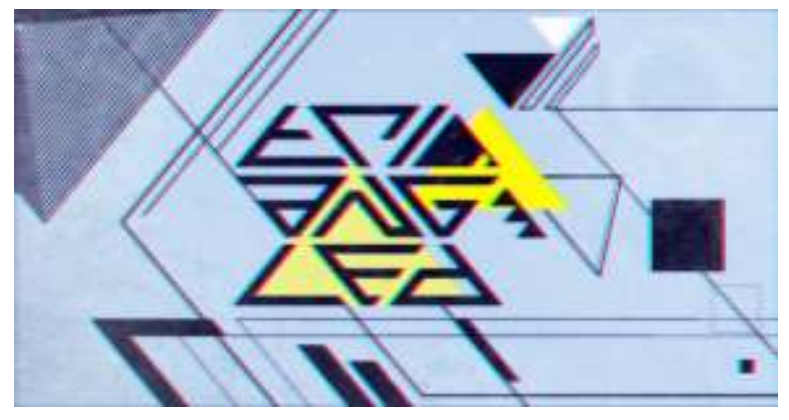

Gambar 6: Visualisasi untuk promosi

Sumber: Dokumentasi Pribadi (2009) 


\section{Aplikasi Desain Huruf}

Font yang bernama 'Angled' tersebut akhirnya menjadi karya visual baru dengan penyesuaian karakteristik dari bentuk-bentuknya yang mempunyai kesan modern. Dengan visualisasi dan kesan yang baru tersebut, font ini telah diaplikasikan pada media cetak dan juga multimedia interaktif diantaranya adalah video klip dari penyanyi asal Amerika, Kanye West dalam lagunya berjudul 'All of The Lights'. Dan font ini hadir pula dalam identitas sebuah band bernama Dream The Light.

Dilihat dari sisi visual, font 'Angled' yang telah dipakai pada media-media baru tersebut, cenderung digunakan dalam sebuah karya pop (populer) dengan rujukan gaya yang bersifat dinamis dan terkesan techno (berasal dari kata technology).

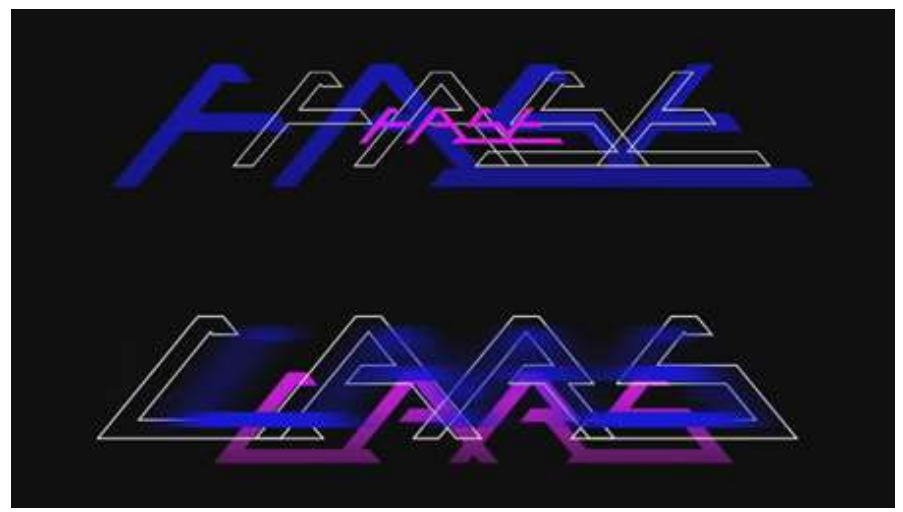

Gambar 7: Pengunaan font dalam video klip milik Kanye West "All of the Lights"

Sumber: Columbia Pictures

\section{Kesimpulan}

Aksara Lontara sebagai salah satu khasanah budaya dalam perkembangan komunikasi dan bahasa tulis suku bangsa Indonesia dapat menjadi sebuah rancangan baru dengan melakukan penyesuaian komunikasi yang telah didominasi oleh huruf Latin. Inovasi pada segi visual mampu mempresentasikan identitas asli dengan bentuk baru sehingga dapat menghasilkan interpretasi dan mengaplikasikan terhadap media digital yang sebelumnya banyak digunakan pada media manual.

Kesulitan yang lahir dari masalah kurang dikenalnya aksara Lontara, memang butuh pembiasaan layaknya huruf Latin yang sudah dikenalkan sejak lama dan digunakan sehari-hari. Namun dengan proses penyesuaian, hal tersebut dapat menjadi celah agar masyarakat yang lebih modern dapat menangkap esensi karakteristik budaya yang mampu diaplikasikan terhadap kemajuan teknologi dan khasanah budaya modern. Sehingga perlu adanya aturan yang mengatur keseluruhan karakter huruf agar dapat diapresiasi oleh khalayak luas untuk mendapatkan anatomi dan sistem penulisan yang teratur. 


\section{Daftar Pustaka}

Burke, Christopher. (1998). Paul Renner: The Art of Typography. London: Hypen Press.

Fauziah, Riza. (2013). Gagasan Pemanfaatan Aksara Lontara Suku Bugis Dalam Bentuk Website. Tugs Akhir. Jurusan Desain Komunikasi Visual Fakultas Desain Universitas Komputer Indonesia, Bandung.

Haswanto, Naomi. 2002. Tinjauan Rupa atas Aksara Batak Toba Sebagai Sumber Gagasan bagi Tipografi Masa Kini. Disertasi. Program Pascasarjana Fakultas Seni Rupa dan Desain, Institut Teknologi Bandung, Bandung. (halaman 23)

Rustan, Surianto. (2011). Hurufontipografi. Bandung: PT. Gramedia Pustaka Utama.

Sihombing, Danton. (2001). Tipografi dalam Desain Grafis. Bandung: PT. Gramedia Pustaka Utama. 